\title{
Políticas anti-migratórias e circulação de "retirante": tessituras entre trabalho e migração nas obras públicas em tempos de secas no Ceará (década de 1950)
}

\author{
Lara Vanessa de Castro Ferreira ${ }^{*}$
}

\begin{abstract}
Resumo
Cerca de dez anos depois da Batalha da Borracha - quando as diretrizes varguistas instituíram uma forte propaganda para impulsionar a ida de trabalhadores nordestinos rumo à extração de látex na Amazônia -, autoridades públicas e particulares cearenses, com reforço do poder público nacional, movimentaram-se para frear a saída de grandes contingentes populacionais do estado, por meio de iniciativas anti-migratórias. Durante as estiagens na década de 1950, a grande medida de fixação de trabalhadores foi a ampla instalação de frentes de serviços emergenciais. Aliás, medida que igualmente combinava com o discurso de racionalizar os socorros aos retirantes sem serviço e sem comida durante as secas. Ao lado disso, pode-se pensar que a migração na rota das obras públicas também tornou-se alternativa de sobrevivência dos próprios trabalhadores que preferiam permanecer próximos aos seus locais de origem a emigrar para outros estados.
\end{abstract}

Palavras-chave: Trabalhadores; Migrantes; Políticas.

\section{Políticas anti-migratórias}

Em 1915, pela primeira vez, o governo federal articulou-se com autoridades públicas e particulares da região atualmente conhecida como Nordeste, para organizar e coordenar um volumoso programa de obras de "combate às secas", a fim de mitigar os problemas sociais avaliados como efeito da estiagem daquele ano. Tais obras, criadas emergencialmente após a declaração daquela seca e conduzidas pela Comissão de Obras Novas Contra as Secas, visavam deliberadamente evitar o êxodo da mão de obra dispersa pelas estiagens, proporcionando ocupação aos trabalhadores, mas também havia a intenção de impedir os tumultos provocados pela chegada de aglomerações de

\footnotetext{
Doutoranda em História Social pela Universidade Federal da Bahia (UFBA). Professora da Universidade Federal do Amapá (UNIFAP). Email:laravcf@gmail.com.
} 
retirantes aos núcleos urbanos, como saques aos comércios, propriedades privadas e repartições públicas. ${ }^{1}$

O emprego de retirantes em obras públicas de grande porte, ou em serviços organizados localmente durante as secas, não era uma novidade desde as últimas décadas do século XIX. Afinal, desde esse período as autoridades passaram a entender que as construções públicas, ordinariamente conduzidas independentemente das secas, poderiam servir ao propósito de aplacar as "agitações" feitas pelos retirantes nas cidades, quando as estiagens ocorriam. Assim, como Frederico Neves (2002) expõe ao longo do seu texto, pode-se dizer que as obras passam também gradativamente a serem consideradas entre as respostas dadas às multidões de retirantes que solicitavam emprego e alimento. ${ }^{2}$

A novidade das políticas ativadas para combater a seca de 1915 foi a intervenção organizada e diretiva do governo federal que, por meio da criação de uma comissão, tomou para si a responsabilidade na execução de frentes emergenciais de trabalho. Chamada de Obras Novas Contra as Secas, essa comissão atuou paralela e autonomamente em relação à Inspetoria de Obras Contra as Secas (IOCS) ${ }^{3}$ até 1919, utilizando regulamentos e até mesmo alguns funcionários dessa instituição, agindo em todos os estados do polígono das secas, dando início a várias obras com o objetivo declarado de ocupar retirantes e conter a migração. Tratava-se, entre outras coisas, de dar maior celeridade à liberação dos recursos vindos do Ministério de Viação e Obras Públicas (MVOP) para o combate às estiagens, garantindo exclusividade e independência na gestão dos recursos.

\footnotetext{
${ }^{1}$ Essas observações são resultantes da minha pesquisa de mestrado, realizada na Universidade Federal da Bahia, entre 2007 e 2009. Nela, estudei política e atuação da comissão Obras Novas Contra as Secas (1915-1919), procurando entender as variadas estratégias de sobrevivência acionadas pelos retirantesoperários enquanto trabalhadores das frentes de serviços daquele órgão, estabelecendo também um contraponto com os anseios e práticas dos engenheiros ligados à comissão. A grande maioria das fontes analisadas são inéditas, sendo que meu contato com essa documentação remonta ao ano de 2004, durante minha graduação em História na Universidade Federal do Ceará - UFC, ocasião em que fui bolsista do projeto de pesquisa MECTSAB, que inventariou parte da documentação do atual Departamento Nacional de Obras Contra as Secas (DNOCS).

${ }^{2}$ Em sua importante pesquisa, Neves estudou acontecimentos de 1877 até a década de 1950, visando demonstrar a consolidação de uma tradição de protestos em tempos de secas. Na concepção do autor, as obras (assim como a doação de alimentos, passagens, etc.) estão entre as respostas do poder público aos movimentos e saques dos retirantes durante as estiagens.

${ }^{3}$ Em 1909 foi criada a Inspetoria de Obras Contra as Secas - IOCS, que organizou a delimitação dos espaços sujeitos as estiagens periódicas. Em 1919 a IOCS passa a IFOCS - Inspetoria Federal de Obras Contra as Secas. Por fim, em dezembro de 1945 foi promovida a reformulação da IFOCS, transformandoa em autarquia, o DNOCS, dando maior autonomia ao órgão.
} 
A partir desse momento, além de aproveitar as construções já existentes para empregar os retirantes, conforme era feito eventualmente, passou-se a estabelecer um plano sistematizado de obras que eram acionadas a cada seca, cuja execução era centralizada pelo governo federal, e que associava os socorros dados aos pobres em tempos de estiagem ao trabalho nas frentes emergenciais. Agora, caberia ao Estado não somente dotar os sertões semiáridos de uma infraestrutura hídrica capaz de suportar as estiagens, como dele seria também recorrentemente cobrado o dever de criar obras especialmente com a finalidade de ocupar e fixar em seus locais de origem milhares de operários.

Essa iniciativa de atacar obras com claros objetivos de evitar o êxodo foi fortalecendo-se ao longo da primeira metade do século XX. Ao lado disso, a política de incentivo e subsídio da migração ${ }^{4}$, tão cara aos representantes políticos e donos de propriedades no XIX, perdeu espaço nos planos governamentais em tempos de secas. No entanto, é bom lembrar que um proposital hiato nesses projetos de Estado, depois de 1915, foi a Batalha da Borracha na Amazônia do início dos anos 1940, quando diversos órgãos públicos instituíram uma forte propaganda para impulsionar a ida de trabalhadores cearenses rumo à extração de látex. ${ }^{5}$

Cerca de dez anos depois, o Estado organizou um plano de obras durante as secas de 1951-1953 e 1958. Este artigo tem como proposta justamente entender essas construções públicas como ferramenta para fornecer ocupação aos retirantes, evitando migrações, fixando ao mesmo tempo trabalhadores dentro dos seus locais de origem, excedente fundamental para conservação do poder econômico e prestigio das autoridades públicas e particulares; além da finalidade de atalhar os conflitos próprios dos problemas sociais descortinados durante as secas.

Ao lado disso, as frentes estreadas em períodos de estiagem serão consideradas, também, como estratégias de sobrevivência elaboradas pelos próprios trabalhadores, um sinal de que pobres não esperavam mais esgotar-se na miséria, antecipavam-se e, muito cedo, procuravam os núcleos urbanos na tentativa de garantir comida e emprego. Se

\footnotetext{
${ }^{4}$ Sobre emigração subsidiada no século XIX ver Secreto (2003).

${ }^{5}$ Sobre os Soldados da Borracha ver Secreto e Costa (2007); e ainda Gonçalves (2008). A instalação da comissão de "Obras Novas", assim como outras frentes de trabalho nas secas posteriores, não cessou absolutamente a migração. Certamente, numerosas pessoas, em diferentes momentos, cruzaram as fronteiras dos estados semiáridos, fosse via passagens subsidiadas, com recursos obtidos pela venda de seus pertences, ou através dos "paroaras" e redes de parentesco. Sobre o ofício dos "paroaras" ver Cardoso (2011). Outras políticas anti-migratórias foram os "campos de concentração" das secas. A esse respeito ver Rios (2006); Neves (1995).
} 
disparar rumo ao norte amazônico ou partir para outros estados foram alternativas aos migrantes daqueles anos, trilhar em busca de trabalho também foi um importante meio de contornar as dificuldades.

Os trabalhadores labutaram na edificação, restauração e conservação de obras organizadas por órgãos como o Departamento Nacional de Obras Contra as Secas (DNOCS) e o Departamento Nacional de Estradas de Rodagem (DNER) nos anos 1950. Foram lotados em obras já em andamento - ditas permanentes, mas especialmente nas acionadas durante as estiagens - chamadas de emergência. Estas, conforme boletim do DNOCS $^{6}$, diferente daquelas, se "destinavam a eliminar o desemprego nos períodos de estiagem", tendo "em vista manter a população no seu próprio ecúmeno", evitando "concentrações humanas improvisadas" e os "inconvenientes do trabalho a grandes distâncias". Daí a necessária “elaboração antecipada" de projetos para serem executados logo que desencadeasse a seca.

Fora a expressa finalidade de ocupar e fixar trabalhadores, admitindo também o incômodo que os agrupamentos de pessoas causavam, as frentes de emergência, assim como em outros anos, carregavam características diferentes das demais obras públicas. Mesmo ativadas com créditos especiais, sustentadas com o discurso do amparo, seus rarefeitos orçamentos não davam conta de empregar os numerosos retirantes. $\mathrm{O}$ excesso de braços também reduzia a receita que resultava em parcos provimentos aos operários. Eram obras geralmente pequenas, pensadas para durar o ano de seca, por isso ofereciam terríveis condições de alojamento, insalubres e improvisados, onde faltava água até para beber.

Diversos documentos do DNOCS, fontes literárias, entrevistas e jornais atestam que as condições de existência dos operários nas frentes de emergência eram muito diferentes, na verdade bem piores, se comparadas as outras obras. Longe de pretendermos fazer uma espécie de comparação da "desgraça" - o que seria problemático e objetivamente muito difícil - devemos considerar que havia diferentes tipos de construções destinadas ao "socorro público", cujas distinções implicavam, também, em peculiaridades no universo do trabalho que nelas se organizava. Ao reunilas numa mesma esteira, devemos cuidar para não sintetizar e homogeneizar também as experiências dos obreiros nos períodos de secas.

\footnotetext{
${ }^{6}$ PASSOS, José Candido Castro Parente Pereira. Departamento Nacional de Obras Contra as Secas. Boletim Institucional DNOCS, Rio de Janeiro, v. 19, n. 3, p. 32, fevereiro de 1959.
} 
De qualquer modo, na década de 1950, como em outros anos, os retirantes foram protagonistas na produção de uma volumosa estrutura em todo Nordeste. O discurso oficial de assistência, pelo emprego nas obras, turva a visão para o fato de que milhares de trabalhadores, solicitando alimento e comida, construíam alternativas para os seus problemas e acabavam por modificar os cenários das ruas, das repartições públicas e dos arredores das frentes de serviços. Dentro delas, continuavam por intervir amplamente com sua força de trabalho operando em açudes, estradas, perfuração de poços, instalação de canais de irrigação, redes de energia, postos de piscicultura, escolas, igrejas, entre outros.

Em 1951, conforme o Correio do Ceará $^{7}$, para evitar que trabalhadores migrassem para a capital cearense e outras cidades, entre outros, construções foram concentradas em pontos estratégicos do interior, distribuindo comida e colocação em serviço de emergência. Além da pequena e média açudagem, como explana o diretor Vinícius Berredo em relatório, centenas de rodovias foram iniciadas e prosseguidas quando "[...] a crise climática obrigou a dar início a novos serviços para permitir o acesso de flagelados que afluíam à procura de trabalhos". (DNOCS, 1951, p. 4). ${ }^{8}$

Grandes açudes como o Araras, o Orós e o Banabuiú no Ceará, com projetos empacados, finalmente iniciaram suas construções com o alarde das secas, tornando-se também centros de "socorros públicos". O diretor da divisão técnica do DNOCS, engenheiro Rômulo Campos, justificou a construção do grande açude Araras em 1951 como projeto de "primordial importância para o Estado do Ceará" que, projetado como obra permanente, teria duplo papel naquela seca. Quando concluído, o Araras tornaria a zona norte do estado preparada "contra os efeitos das secas", beneficiando pessoas em atividades de cultivo em vazantes, piscicultura e irrigação, abastecendo com água as cidades e evitando prejuízos "aos proprietários de terras". Ao mesmo tempo, serviria como frente de trabalho durante a sua construção, "em vista do grande afluxo de trabalhadores" de municípios próximos procurando ocupação durante aquela estiagem (1 ${ }^{\text {a }}$ DR DNOCS, 1951). ${ }^{9}$

\footnotetext{
${ }^{7}$ BIBLIOTECA PÚBLICA MENESES PIMENTEL. Setor de microfilmagem e Setor de Jornais. Getúlio cada vez mais impressionado com a ameaça da seca no Ceará. Correio do Ceará, Fortaleza, 09 mar. 1951.

${ }^{8}$ DEPARTAMENTO NACIONAL DE OBRAS CONTRA AS SECAS. Relatório de obras executadas em 1951. (apresentado pelo Diretor Berredo Vinícius). Rio de Janeiro: DNOCS/MVOP, 1951.

${ }^{9} 1^{\text {a }}$ DR DNOCS. Açudes Públicos Ceará. Açude Araras. Correspondência enviada pelo engenheiro Rômulo Campos ao Diretor Geral do DNOCS. 11 de agosto de 1951.
} 
Entretanto, por mais que obras tenham sido iniciadas em diversos cantos do Ceará, objetivando ocupar retirantes e evitar a saída da mão de obra para outros estados, elas não foram suficientes para abarcar a cifra de necessitados atingidos pela seca. Os problemas ocasionados pelas escassas vagas de empregos nas construções frente ao número de pessoas que necessitavam delas chegaram aos ouvidos do governo no Rio de Janeiro. Aquele excedente de braços do campo poderia ir embora, exatamente o que o Estado não desejava naquele momento. Desse modo, segundo Camargo (1984), José Américo, Ministro da Viação e Obras Públicas de 1951-1954, tornou urgente "uma campanha" que inviabilizasse a saída de "famílias inteiras" dos seus estados de origem.

Mesmo com mudanças nos quadros políticos, a obsessão por integrar as regiões e garantir a imobilidade dos seus trabalhadores atravessou os anos 50. Em 1958, aquela que ficou conhecida como a "grande seca" motivou uma reunião que agregou setores públicos do DNOCS, DNER, exército, Comissão Federal de Abastecimentos e Preços (COFAP), Instituto Nacional de Imigração e Colonização (INIC), Ministério do Trabalho, da Viação, e Obras Públicas e representantes particulares da Conferência Nacional de Bispos, da Legião Brasileira de Assistência e da Fundação das Pioneiras Sociais, esta tendo à frente Sarah Kubistchek. A resolução amplamente apoiada por essa elite política, social e religiosa, considerada imediata, foi "assistir" os pobres por meio do emprego em diversas obras que igualmente serviriam para "fixar" o trabalhador do campo. A decisão, portanto, foi de liberar créditos especiais para intensificação, ampliação e antecipação de obras ocupando todos que procurassem "os escritórios do DNOCS e do DNER", especialmente "onde maior fosse" a "aglomeração", "em obras tão próximas quanto possível" dos seus locais de moradia, "a fim de evitar o êxodo" (PASSOS, 1958, p. 34). ${ }^{10}$

Dessa forma, o DNOCS iniciou cerca de 145 frentes de trabalho (PASSOS, 1958, p. 34-35). ${ }^{11}$ em todo interior do Nordeste e o DNER recebeu "instruções para reter" o retirante mediante a construção de rodovias, com especial encargo de "[...] impedir o êxodo desordenado e tulmutuado para o sul”. (PASSOS, 1959, p. 36). ${ }^{12}$ Além

\footnotetext{
${ }^{10}$ PASSOS, José Candido Castro Parente Pereira. Ministério da Viação e Obras Públicas. Departamento Nacional de Obras Contra as Secas. Boletim Institucional DNOCS, Rio de Janeiro, v. 18, n. 2, novembro de 1958.

${ }^{11}$ PASSOS, José Candido Castro Parente Pereira. Ministério da Viação e Obras Públicas. Departamento Nacional de Obras Contra as Secas. Boletim Institucional DNOCS, Rio de Janeiro, v. 18, n. 2, novembro de 1958.

12 PASSOS, José Candido Castro Parente Pereira. Ministério da Viação e Obras Públicas. Departamento Nacional de Obras Contra as Secas. Boletim Institucional DNOCS, Rio de Janeiro, agosto de 1959.
} 
disso, o DNER, em alguns momentos, também agiu em cooperação com a polícia na fiscalização da saída de retirantes pelas fronteiras do Nordeste. ${ }^{13}$ Tudo isso cooperou para o entendimento das diversas motivações para a ocorrência das frentes de trabalho, instrumento fundamental das politicas anti-migratórias: as aglomerações de sertanejos em busca por trabalho e comida, fazendeiros ansiosos por não perder braços para o êxodo e valorizar economicamente suas terras, políticos desejosos de verbas em seus municípios para assegurar melhoramentos e votos.

O próprio ajuntamento de pessoas nas sedes dos municípios que receberiam obras e ao redor delas já exercia forte pressão nos políticos locais, comerciantes e responsáveis pela organização das frentes de socorros. O excedente populacional sem serviço em tempos de secas era tão impactante, em termos numéricos, que muitas vezes o engenheiro tinha que propor a organização, simultaneamente, de variados serviços numa mesma obra ou abertura de novas construções. Contudo, a execução das obras em tempos de estiagens ia além da finalidade de atender aos reclames em forma de "avalanches" exercidos pela população.

Ao implantar as frentes, o MVOP tinha a possibilidade de contribuir para reter in loco trabalhadores que poderiam sair dos seus estados durante as secas, e essa contenção certamente beneficiava políticos locais e donos de terras. Transformar os açudes em pequenos centros de trabalho por meio da implementação de culturas em vazantes, piscicultura, irrigação, como foi alegado na justificativa da construção do Araras (1 $1^{\text {a }}$ DR DNOCS, 1951) $)^{14}$, citada acima, era uma forma de fixar o sertanejo em seus locais de labuta, também em anos de normalidade da produção para o trabalho nas fazendas. Ademais, lembremos que açudes e estradas eram benfeitorias de serventia para as propriedades rurais, diminuindo, conforme admite o próprio engenheiro do Araras, os prejuízos dos "proprietários de terras".

Claramente, quando o Poder Executivo, por meio do MVOP e com o apoio dos governos estaduais implantava frentes no interior, não tinha a intenção somente de dar trabalho e evitar a fome, mas também manter os retirantes longe dos espaços públicos e privados, atalhando desordem e confusão. Paralelo a isso, também existia o desígnio de evitar o deslocamento dos trabalhadores sob pena de esvaziar a reserva de mão de obra do campo. Com efeito, esse objetivo se torna mais claro se observamos, por meio das

13 BIBLIOTECA PÚBLICA MENESES PIMENTEL. Setor de microfilmagem e Setor de Jornais. Exploração de flagelados por motorista. Correio do Ceará, Fortaleza, 03 abr. 1951.

$141^{\text {a }}$ DR DNOCS. Açudes Públicos Ceará. Açude Araras. Correspondência enviada pelo engenheiro Rômulo Campos ao Diretor Geral do DNOCS. 11 de agosto de 1951. 
notícias divulgadas na imprensa e também nas fontes orais, o hábito corriqueiro pelo qual autoridades públicas e particulares encaminhavam listas de trabalhadores para que os funcionários do DNOCS ou DNER os incluíssem nas obras.

Ocorre que, fora dos tempos de estiagem, ainda era possível manter algumas práticas paternalistas, mas, ao contrário, cada vez mais, em tempos de secas, os donos de terras não suportavam os encargos da crise ou queriam desfazer-se deles. Como desde o fim do XIX o Estado fortaleceu a prática de empregar retirantes em obras públicas e subsidiar passagens para outros estados etc., a ideia é a de que ele assume a obrigação da assistência aos retirantes, que antes era dos fazendeiros. Portanto, o poder privado, com o reforço da imprensa, entende, cada vez mais, que ao governo cabe a obrigação de resolver o problema dos sertanejos retirantes nas secas.

Visto que os donos de terras tivessem interesse em manter os seus trabalhadores num raio de distância ao alcance de sua propriedade, eles contavam com a iniciativa do Estado de criar frentes de serviços que acolhessem os trabalhadores durante os tempos de crise. O ministro José Américo, contudo, conforme Camargo (1984, p. 226), alegava que um açude não conseguia "absorver" toda "massa" que se desprendia das fazendas, notando inclusive que os terratenentes os "exploravam", livrando-se dos seus "moradores". Com efeito, mantendo os sertanejos não muito distantes dos seus lugares de residência e trabalho, mas suficientemente longe de suas obrigações paternalistas, logo que o período de estiagem fosse atravessado, os braços desses trabalhadores estariam de volta à lida no campo, conforme queriam os fazendeiros. Mas não era só isso: a migração em massa poderia significar algo além da perda da força de trabalho, representando, em acréscimo, a perda dos domínios eleitorais.

Justificadas no auxílio e fixação dos sertanejos, os trabalhadores do semiárido erguiam uma estrutura, que combinava, também, com os propósitos discutidos naquele período rumo à integração nacional, e a correção dos desníveis socioeconômicos entre as regiões. Enquanto no Sudeste o Plano de Metas priorizou a indústria com foco na implantação do parque automobilístico em São Paulo, no Nordeste e na Amazônia, objetivando ligar áreas "isoladas" ao "centro" do país, ocorreu a intensificação da construção de rodovias, absorvendo grandes parcelas orçamentárias. De modo geral, acreditava-se que o desenvolvimento econômico nacional seria o resultado do fortalecimento da indústria e de alguma transferência de capital para regiões "periféricas", fosse pelo investimento em projetos de fomento da economia agrícola, 
fosse pela abertura de novas estradas, ou ainda pela implantação de centenas de obras públicas nas capitais e no interior (MONTENEGRO, 1985).

Os volumosos créditos liberados em tempos de secas, portanto, eram a desculpa ideal para manter obras com o objetivo de controlar a saída de braços, assim como se constituíam em investimento no âmbito da política desenvolvimentista. Espalhar construções pelo interior do país também era um reflexo da sede por integração e ocupação dos espaços supostamente "vazios", obsessão que percorre a década de 1940 e 1950, representada pela construção de Brasília no governo de Juscelino Kubitschek.

A necessidade de povoamento e fixação dos trabalhadores concorria para a ambicionada ocupação dos territórios do sertão do Brasil, tarefa tida como uma das mais importantes no projeto de integração nacional. No Ceará, a percepção das estiagens como fenômeno natural que tornava o lugar atrasado pelo ambiente inóspito era algo que seria controverso apenas de modo parcial pelo uso do saber técnico-científico. Mesmo num meio considerado, sazonalmente, inapropriado para viver e labutar, o governo não considerava o sertão cearense tão vazio assim. $\mathrm{O}$ medo era do despovoamento que as secas poderiam ocasionar. Por isso as iniciativas eram organizadas mais no sentido de fixar os retirantes em obras públicas pelo interior nos tempos de calamidades climáticas.

As obras emergenciais, portanto, desejavam tornar possível um manejo sobre os braços nordestinos. Assim, fazendeiros poderiam manter mão de obra disponível e beneficiar com melhoramentos suas terras; e políticos assegurariam aos seus municípios recursos abonados, melhoramentos e votos. Paralelamente, as frentes de trabalho também ocorriam graças a esses movimentos migratórios em tempos de secas, que constrangiam as autoridades a lidar com o problema. Dessa forma, deslocar-se no rastro das obras públicas também pode ser pensado como estratégia de sobrevivência dos trabalhadores que não pretendiam, por motivos diversos, cruzar as fronteiras dos seus estados de nascença.

\section{Ativismo retirante}

Sozinhos ou em grupo, os retirantes do romance Os Cassacos percorriam os caminhos que levavam aos locais onde eram realizados os alistamentos. "Nas margens da estrada, ao abrigo do sol, embaixo de juazeiros e oiticicas, muitas famílias esperavam o frescor da noite para prosseguir na penosa caminhada [...]" rumo aos locais "[...] onde 
estavam alistando a gente para as obras públicas." (BARREIRA, 1976, p. 85). Com a seca declarada, "as primeiras levas de migrantes" já enchiam as estradas "poeirantes em busca de trabalho". Ao ver todo seu roçado perdido, Zuca Machado, personagem da literatura, turva-se de tristeza. Ele também haveria de ir, mesmo com a "recordação amarga" de suas experiências anteriores como operário da "farinha azeda, carne rançosa, feijão duro", "da fome, da febre e do miserável hospital” nas frentes de serviço. O personagem considera que não haveria outro "jeito" senão “[...] iscapá nas construção [sic] do governo.” (BARREIRA, 1976, p. 13).

As "levas de retirantes" descritas na obra do jornalista Luciano Barreira ${ }^{15}$, "buscavam serviços nas obras do açude Banabuiú ou na construção da estrada Pirangui” durante a estiagem de 1958. As desventuras dos seus personagens guardam propositais referências ao cotidiano dos retirantes da década de 1950. Por isso, embora trate-se de um romance de ficção, Os Cassacos é uma importante fonte histórica, não apenas por ser contemporânea ao contexto social e histórico objeto desta pesquisa, mas principalmente pelo fato dos episódios narrados pelo autor guardarem intencional sensibilidade e empatia histórica em relação às situações vividas por retirantestrabalhadores na década de 1950.

Interessante perceber que Zuca Machado aparece no texto um tanto quanto resignado, sem opções diante dos problemas que chegavam. Mesmo com todas as lembranças "amargas", a única escolha seria seguir ao lado dos demais para as frentes de emergência. Era bem possível que a alternativa mais viável naqueles anos de estiagem, para alguns sertanejos, fosse realmente o trabalho nas obras públicas para garantir o sustento para si e para família.

Decerto, as pessoas avaliavam as escolhas dentro do horizonte de possibilidades que as cercavam. Se disparar para outros estados poderia ser atrativo e objeto de desejo para uns, representava, para outros, a distância da família, o desconhecido, uma longa e dura jornada. Nessa lógica, pode-se dizer que, na intenção de evitar as mazelas de um percurso longo para outros estados, muitos sertanejos procuravam alistamentos nas obras que pudessem fornecer trabalho. É importante lembrar que a memória sobre as retiradas é marcada pelos registros de mortes, doenças, inanição e suicídios. Assim, levando em consideração que as pessoas já tinham

\footnotetext{
${ }^{15}$ Nascido em Fortaleza em 1926, Luciano Barreira foi jornalista, escritor e integrante do PCB (Partido Comunista Brasileiro). Trabalhou nos jornais Gazeta de Notícias, Diários Associados e O Democrata e aos 48 anos publicou seu primeiro romance Os Cassacos, aproveitando-se de rascunhos, matérias, notas e observações realizadas em campo na seca de 1958.
} 
informação sobre os problemas associados a uma travessia comprida, especialmente rumo à Amazônia, arriscar-se numa jornada mais curta e seguir o rastro das obras públicas, poderia ser a esperança de menos sofrimento.

De qualquer maneira, o retirante recorrentemente aparece em literaturas, memórias e outras obras em meio a jornadas incríveis, fugindo da fome, sofrimento e morte, sem saber ao certo onde vai aportar. Sempre age espasmodicamente, institivamente, sem refletir sobre os próprios feitos. A alternativa apontada para contornar tais péssimas condições de existência, que, aliás, pareciam só existir nos momentos de estiagem, era a migração. Por isso, ao estudar a ida de pessoas para os serviços da açudagem, devemos considerar o cenário político e as ações do Estado, as condições sociais e materiais do indivíduo, mas também seus motivos e suas escolhas.

Antes mesmo da declaração oficial da seca, a imprensa já noticiava, em 1951, o ajuntamento de pessoas nas ruas em diferentes cidades do estado do Ceará. Conforme o jornal Correio do Ceará (BIBLIOTECA PÚBLICA MENESES PIMENTEL, 1951) ${ }^{16}$, órgão dos Diários Associados nesse estado, o prefeito de Acaraú comunicou que "habitantes procuravam a sede municipal à procura de trabalho e alimento" sob o "espectro da fome". Os comerciantes cearenses, dizia o periódico, já falavam "assustados" em "serem saqueados" e somente obras de emergência, algo de que todos os municípios necessitavam, evitaria o surgimento de "mendigos", "epidemias", "saques" e "fome". 17

A imprensa, muitas vezes, reforçou a imagem de retirantes como infelizes, desgovernados pela fome, desgraçados pela seca. Os retirantes, porém, por meio do cenário de incerteza provocado pela aglomeração de gente, garantiam visibilidade. A tática de distribuição de créditos, regulares ou especiais, para obras públicas no interior pertencia a uma lógica de racionalizar os socorros, mas também de acalmar os ânimos dos retirantes, impedindo que os efeitos das aglomerações, que eles provocavam, pudessem chegar aos principais centros urbanos e comerciais. Interessante lembrar que,

\footnotetext{
16 BIBLIOTECA PÚBLICA MENESES PIMENTEL. Setor de microfilmagem e Setor de Jornais. Também de Nova Russas chegam as mais desoladoras notícias de fome, Correio do Ceará, Fortaleza, 16 mar. 1951.

1719 de março, dia de São José, que para os sertanejos marca o ano chuvoso ou seco, coincide também com o equinócio de outono. Dependendo da baixa pressão atmosférica e da temperatura das águas do oceano, durante o equinócio, chuvas caem sobre os estados do Nordeste (principalmente os localizados ao norte), determinando se a partir dali novas chuvas continuarão a ser despejadas. Portanto, se até dia 19 de março não chover a seca é oficialmente declarada.
} 
prefeitos e comerciantes, propositalmente, também aproveitavam o momento de pânico para noticiar que somente a realização de obras resolveria os problemas.

Já existe uma extensa discussão, realizada por Frederico Neves, acerca das ações da multidão em tempos de secas, especialmente saques, visando garantir remediação aos seus próprios problemas. Desse modo, nosso objetivo neste texto centra-se no sentido de entender as características da migração que se estabelecia rumo às frentes de trabalho, e o quanto ela se constituía como uma estratégia de sobrevivência em diferentes momentos ao longo da estiagem. Sobre isso, é interessante determo-nos em alguns acontecimentos bastante elucidativos.

No fim do mês de março de 1951, depois das primeiras ocorrências envolvendo retirantes em busca de serviço e dos pedidos de obras pelas autoridades locais, o diretor do DNOCS, Vinícius Berredo, prometeu trabalho a todo "flagelado", assim noticiava o jornal O Povo em 23 de março de $1951 .^{18}$ Três dias depois, o mesmo periódico transcreveu uma correspondência enviada à sua redação, na qual constava um telegrama emitido pelas "autoridades locais" de Canindé, a pedido dos retirantes, ao diretor do DNOCS. As autoridades informavam à Berredo que "mais de mil chefes de família" solicitavam serviços. Salientando, contudo, que qualquer "medida tardia" seria "contraproducente" diante do volume de famílias que já reclamavam trabalho.

No entanto, as andanças dos retirantes em busca de soluções para os seus problemas continuavam, o que deixava a capital e as cidades do interior lotadas de migrantes. Em abril já haviam sido arregimentados pelas obras mais de 20 mil retirantes só no estado do Ceará, mesmo assim, os reclames por trabalho vinham de todos os cantos do estado, mas as respostas, conforme alega um vigário da cidade de Itapagé, precisavam ser mais palpáveis (BIBLIOTECA PÚBLICA MENESES PIMENTEL, 1951). ${ }^{19}$

Somente a notícia de uma construção já era suficiente para que várias pessoas acudissem de todos os cantos. Em maio de 1951, conforme o Correio do Ceará ${ }^{20}$, em Massapé, o aviso da construção do reservatório Acaraú-Mirim, ordenado ao DNOCS pelo ministro da Viação e Obras Públicas, Sousa Lima, durante uma visita àquela

\footnotetext{
${ }^{18}$ BIBLIOTECA PÚBLICA MENESES PIMENTEL. Setor de microfilmagem e Setor de Jornais. O Governo dará trabalho a todo flagelado. O Povo, Fortaleza, 23 mar. 1951.

${ }^{19}$ BIBLIOTECA PÚBLICA MENESES PIMENTEL. Setor de microfilmagem e Setor de Jornais. Muito mais seca a Zona Norte. Correio do Ceará, Fortaleza, 26 maio 1951.

${ }^{20}$ BIBLIOTECA PÚBLICA MENESES PIMENTEL. Setor de microfilmagem e Setor de Jornais. Ataque a propriedade privada. Correio do Ceará, Fortaleza, 30 maio 1951.
} 
cidade, fez afluir um grande número de retirantes. Em poucos dias a conversa se espalhou e a cidade já estava abarrotada. Entretanto, a obra não foi iniciada nos dias seguintes, como prometeu o ministro, e em decorrência disso, trabalhadores concentraram-se nas ruas solicitando "auxílio e emprego ao comércio e às autoridades". Alguns deles, quem sabe cansados de esperar socorro, saquearam propriedades, abatendo "reses", em "alguns casos, na presença dos próprios donos" (BIBLIOTECA PÚBLICA MENESES PIMENTEL, 1951). ${ }^{21}$

O ano de 1953 e 1958 foram outros anos de estiagens prolongadas. Aliás, na grande seca de 1958 as chuvas escassearam cedo e os trabalhadores não esperaram que os meios de subsistência desaparecessem para procurar auxílio governamental. Mais uma vez, os retirantes dirigiram-se aos núcleos urbanos, especialmente dos municípios onde se localizavam obras públicas em andamento e promessas de novas frentes. Cidades como Itapipoca (com três rodovias), Sobral (com três açudes e duas rodovias), Pentecoste (com um açude, uma rodovia e um canal de irrigação), Senador Pompeu (com duas rodovias) e outros municípios que concentravam construções de estradas ou estavam nas imediações de obras públicas como Itapajé, Irauçuba, Limoeiro, Ipueiras, Iguatu, Granja e Icó, foram cenários de chegadas massivas de retirantes à procura de trabalho e alimento (MINISTÉRIO DA VIAÇÃO E OBRAS PÚBLICAS, 1953). ${ }^{22}$

Em 18 de março de 1958, um dia antes da data limite para a confirmação oficial de mais uma temporada de seca, retirantes já chegavam às cidades. Conforme o Correio do Ceará $(1958)^{23}$, as pessoas que se deslocaram para Iguatu buscavam emprego e o prefeito local ocupou cerca de 700 homens na tentativa de precaver-se e evitar qualquer situação mais problemática. No mesmo dia, muitos retirantes desejosos de vagas ocuparam a sede do município de Lavras da Mangabeira, dirigindo-se inclusive à casa do prefeito. Enquanto isso, os "pobres" do município de Pereiro, em vez de querer serviços em obras públicas, retiravam-se rumo ao "Amazonas, Paraná e outros estados da federação". As cidades e as obras, desse modo, não eram o único rumo ambicionado pelos migrantes e isso deixava as autoridades particulares e públicas

\footnotetext{
${ }^{21}$ BIBLIOTECA PÚBLICA MENESES PIMENTEL. Setor de microfilmagem e Setor de Jornais. Ataque a propriedade privada. Correio do Ceará, Fortaleza, 30 maio 1951.

${ }^{22}$ MINISTÉRIO DA VIAÇÃO E OBRAS PÚBLICAS. Relatório das atividades de 1952. (apresentado ao Presidente da República pelo Eng. Álvaro de Souza Lima - ministro da Viação e Obras Públicas). Rio de Janeiro: MVOP/Serviço de Documentação, 1953. Cf. jornais: O Povo, O Democrata, Correio do Ceará, meses de março e abril de 1953. Correio do Ceará (27/03/1958 e 18/03/1958); Gazeta de Notícias (06/04/1958 e 07/08/1958).

${ }^{23}$ BIBLIOTECA PÚBLICA MENESES PIMENTEL. Setor de microfilmagem e Setor de Jornais. Flagelados famintos invadem cidades. Correio do Ceará, Fortaleza, 18 mar. 1958.
} 
preocupadas. Na iminência de não serem alocadas obras suficientes para aproveitar esses sertanejos e mantê-los no interior do Ceará, o Instituto Nacional de Emigração e Colonização, via imprensa, já alarmava sobre a possibilidade de perda de "30 mil pessoas" (BIBLIOTECA PÚBLICA MENESES PIMENTEL, 1958). ${ }^{24}$

O movimento de pessoas em busca de trabalho e comida era mais intenso nos meses de março e abril e se localizava especialmente nos municípios que estavam iniciando as obras, ou esperavam recebê-las em cidades com forte comércio e na capital, Fortaleza. No segundo semestre, porém, outro rumo era mais certeiro: as construções já em andamento. A migração seguia o rastro das frentes de emergência, mas as sedes dos municípios voltavam a ser cenários das chegadas massivas caso serviços fossem suspensos, pagamentos, e assim o provimento de alimentos escasseasse.

De julho a outubro de 1951 o jornal O Democrata noticiou alguns episódios. Em 31 de $\operatorname{agosto}^{25}$, cerca de 500 retirantes dirigiram-se aos canteiros da rodagem Acaraú-Itapipoca, onde somaram-se aos trabalhadores dispensados das obras, solicitando emprego. Em 16 de outubro ${ }^{26}$, grupos de sertanejos dirigiram-se ao alistamento das obras do açude Assunção. Depois, frustrados por não conseguirem vagas, chegaram maciçamente à cidade Itapipoca. Conforme correspondências do DNOCS, logo que foram iniciadas as construções da estrada de rodagem que ligava o açude Aires de Souza ao açude Araras, diversos grupos de pessoas aglomeraram-se próximos aos seus canteiros. Por telegrama enviado ao DNOCS, o prefeito afirmou que os pobres, especialmente as crianças, pereciam de fome diariamente nas vias da cidade e, não suportando mais as condições cotidianas, “[...] cerca de quinhentas pessoas invadiram o depósito de feijão do governo tirando o que conseguiram." ( $1^{\text {a }}$ DR DNOCS, 1951). ${ }^{27}$

Nas secas da década de 1950, os sertanejos, como já era costume, puseram-se em circulação em busca de remediar seus problemas. Em movimento, os retirantes evidenciavam com suas ações uma estrutura social, política e econômica problemática.

\footnotetext{
24 BIBLIOTECA PÚBLICA MENESES PIMENTEL. Setor de microfilmagem e Setor de Jornais. Mínimo trinta mil cearenses deixarão estado assolado pela seca. Gazeta de Notícia, Fortaleza, 01 abr. 1958.

25 BIBLIOTECA PÚBLICA MENESES PIMENTEL. Setor de microfilmagem e Setor de Jornais. S/Título. O Democrata, Fortaleza, 31 ago. 1951.

26 BIBLIOTECA PÚBLICA MENESES PIMENTEL. Setor de microfilmagem e Setor de Jornais. S/Título. O Democrata, Fortaleza, 16 out. 1951.

$271^{a}$ DR DNOCS. Açudes Públicos Ceará. Açude Araras. Telegrama enviado pelo prefeito de Cariré (CE), 6 de novembro de 1951.
} 
A seca, de forma isolada, não produzia sequelas tão desastrosas. A própria estrutura fundiária e a agricultura tradicional contribuíam fortemente para desequilibrar a lógica econômica da família sertaneja, na qual o costume era produzir para o gasto e/ou um mercado local. Fora isso, uma série de "obrigações sociais das funções economicamente peculiares àquele grupo", ou seja, a "economia moral" daqueles pobres (THOMPSON, 1998, p. 152.), era desmantelada. A obrigação de o trabalhador prover sua família era inviabilizada ao mesmo tempo em que as relações de proteção que consistiam no "dever" dos mais cheios de posses assistirem os menos abastados - os trabalhadores que labutavam em suas terras, quando a produção para o sustento fosse rarefeita - eram impossibilitadas com a duração da falta de chuvas (NEVES, 2002). Durante os seus trajetos, os trabalhadores reclamariam assistência e ajuda de quem os pudesse socorrer.

Além disso, outras características dessa migração na rota das obras públicas devem ser elaboradas. A circulação de pessoas era mais intensa nos meses que se seguiam à declaração da seca. Março encerra as chances de inverno. E só depois disso os pedidos de verbas de emergência eram efetuados, para, entre outros, investir em ativação de frentes que pudessem fornecer ocupação aos retirantes. Dessa forma, esses meses eram críticos: perda de plantações, morte de gado, expectativa de fome, somavam-se à ansiedade quanto às ações governamentais, que às vezes atrasavam, provocando as aglomerações de trabalhadores.

Algo a ser considerado é que já existia o hábito de procurar os núcleos urbanos quando as secas estreavam (NEVES, 2002). Para os desejosos de assegurar ocupação em obras públicas era necessário caminhar para as cidades e por mais que as ações em prol disso não se encerrassem nas sedes dos municípios, era por aí que ganhavam força. Nesses lugares era possível dar maior visibilidade aos seus sentimentos e anseios. Afinal, a cidade era o lugar das prefeituras, das residências dos políticos, igrejas, câmaras de vereadores, casas comerciais e espaços de deliberações políticas, enfim, onde acreditava-se que os problemas podiam ser resolvidos. Como percebemos também, a chegada dos retirantes despertavam sentimentos diversos. Moradores, proprietários de casas comerciais, autoridades religiosas e políticas, solidarizavam-se, atemorizavam-se. A partir de experiências de outras secas, os citadinos sabiam que, chegando às cidades, as movimentações dos sujeitos em busca de trabalho não tardavam, fosse em forma de ameaça ou ação.

Depois de se movimentar nas cidades, marchar-se em busca de trabalho e comida mais energicamente nos lugares que exatamente concentravam essas 
oportunidades, ou seja, nos arredores das obras e dos seus fornecimentos. Então, a circulação de pessoas dava-se nas cidades com comércios mais abonados, mas especialmente em municípios, grandes ou pequenos, que abrigavam as frentes de serviços, seus escritórios de alistamentos, ou que estavam na iminência de estrear obras de emergência. É inacreditável, entretanto, que os sertanejos aparecessem aqui e ali, ajuntando-se nesses lugares, como "fruto dos deuses". As notícias, os boatos, as redes de parentesco, as relações de compadrio eram fundamentais no desenho dos aspectos dessa migração. Os trabalhadores do campo, portanto, não se desfaziam de seus pertences e deixavam seus lares, às vezes sem a família, sem refletir sobre seus feitos, sobre seus destinos, sem ter a mínima noção de onde poderiam aportar.

Ao tratar do deslocamento de pessoas para a Amazônia, Antônio Alexandre Isidio Cardoso (2011) trata da "circularidade de informações" que conformavam as redes de contato entre as pessoas que migravam. Sertanejos trilhando seus rumos à procura de trabalho também valiam-se das informações que circulavam, especialmente dos boatos que circundavam as comunidades para chegar aos seus destinos. Não é de admirar que em muitos episódios, antes mesmo da chegada das equipes técnicas, os retirantes já estivessem presentes no lugar que abrigaria os canteiros de obras.

A passagem de políticos nas cidades com promessas de obras, como foi o caso da visita do ministro da Viação e Obras Públicas, Sousa Lima, à cidade de Massapê, fazia com que aquelas se tornassem pontos de convergência de pessoas. As notícias se espalhavam muito rapidamente e as caravanas afluíam de todos os cantos, até dos lugares mais distantes. Era possível, também, que as pessoas soubessem de algumas novidades por meio da imprensa. Aliás, os jornais, as declarações oficiais, as mensagens políticas eram importantes meios de notificações dos lugares de alistamentos e das realizações das obras e alimentavam constantemente a disseminação dos boatos.

As relações de compadrio, as redes de parentesco e sociabilidade também eram aspectos dessa movimentação. A partir da fala de Rosa Tomé ${ }^{28}$, e de outros entrevistados, entende-se que as pessoas se valiam dessas redes para terem definições dos lugares das obras e, também, mais facilmente garantir emprego. Os retirantes tinham que, estrategicamente, "se chegar a um homem grande" ou ao prefeito para "se

\footnotetext{
${ }^{28}$ Rosa Tomé Ferreira na seca de 1958 estava empregada numa casa que funcionava como local de alistamento, possibilitando a referida presenciar alguns acontecimentos durante a inclusão de trabalhadores nas frentes de serviços de emergência da seca. José Ferreira. Entrevistado por Lara Vanessa de Castro Ferreira, 11 out. 2008. Rosa Tomé Ferreira. Entrevistado por Lara Vanessa de Castro Ferreira, 14 jun. 2012.
} 
alistar", relatou Rosa Tomé. Uma parte dos trabalhadores que entrevistei obteve conhecimento dos locais das obras por meio dos boatos e garantiu obter emprego a partir das informações e indicações de familiares, parentes, compadres, ou colegas que já estavam trabalhando nas obras e enviavam notícias de novos alistamentos ou vagas abandonadas por operários.

Milton Cunha ${ }^{29}$, por exemplo, utilizou-se de uma prática não incomum de comprar a caderneta de trabalho de um sujeito que abandonou o serviço de construção de uma estrada, devido a obra ter se distanciado muito de sua casa. José de Castro ${ }^{30}$ também contornou sua dificuldade de conseguir emprego dessa forma. Trabalhadores que retornavam periodicamente às suas moradias para visitar e prover a família, ou que enviavam notícias aos amigos e familiares os boatos das vagas ociosas, ampliação abundante de oferta de serviços, ou novos alistamentos, chegavam a lugares distantes. Milton e José, porém, valeram-se não somente do envio de informações dos colegas sobre a vaga em aberto, como também da descrição dos operários das suas turmas, que poderiam tê-los delatados, mas não o fizeram; um exemplo de como a perspicácia individual e a cooperação de colegas poderia criar caminhos alternativos para os operários.

Dependendo, algumas vezes, das redes de relacionamento que um sujeito tinha era possível conseguir trabalho com mais facilidade, e mais, era provável que conseguisse incluir outros membros da família. Os encaminhamentos de listas de pessoas por prefeitos, outros representantes públicos e fazendeiros era comum, e mostram, ao mesmo tempo, o interesse das autoridades locais, desejosos de manter não só o poder econômico e político, mas também a astúcia dos trabalhadores, que precisavam saber lidar com relações pessoais, ao se "chegar" a "um grande homem", para obter algo a seu favor. Isso, certamente, também revela a manutenção de aspectos da cultura paternalista do sertão - prática política baseada num sistema de "troca de favores" - no universo das obras de emergência.

A aglomeração de pessoas nas cidades e nos lugares das obras, portanto, era um importante meio na tentativa de garantir trabalho nas obras, mas, as redes de compadrio, de sociabilidades, a perspicácia e astúcia individual são elementos centrais para o entendimento das travessias rumo às obras e a garantia de emprego e

\footnotetext{
${ }^{29}$ Milton Cunha. Entrevistado por Lara Vanessa de Castro Ferreira, 14 jun. 2012.

${ }^{30}$ José de Castro. Entrevistado por Lara Vanessa de Castro Ferreira, 26 set. 2014.
} 
sobrevivência. ${ }^{31}$ Mesmo assim, todas essas táticas não afiançavam aquisição de emprego nas frentes de emergência. Até porque os trabalhadores migravam em busca de alternativas de sobrevivência, desenhavam suas trilhas, mas tinham que lidar com as circunstâncias políticas, econômicas e sociais.

Resultado da racionalização do trabalho, somado ao entendimento de que a lida nas obras públicas era uma alternativa emergencial, aos primeiros sinais do fim da estiagem os próprios operários abandonavam as obras e voltavam para suas atividades costumeiras da lida com a terra, com os animais, com o artesanato, entre outros. O Correio do Ceará informava que "quando" caíam "as chuvas", o sertanejo atirava "fora a picareta oficial", olhava "com desprezo o apontador" e voltava "aos seus roçados" (Correio do Ceará, 01/04/1951). ${ }^{32}$ Portanto, o abandono do trabalho nas obras, com efeito, podia ser um reflexo da não satisfação frente às condições de existência nas obras - moradias precárias, ritmo acelerado, falta de comida e água, ausência da família - e a uma labuta em situações sociais e culturais distintas às dos sertanejos que eram baseadas num sistema de reciprocidade, travado até mesmo entre sujeitos desiguais, que existia no campo.

Entretanto, inúmeras vezes, antes da estiagem findar, obras eram finalizadas ou paralisadas e nem sempre havia condições imediatas que permitam o aproveitamento dos trabalhadores excedentes, provocando uma dispensa em massa. Muitos sertanejos,

\footnotetext{
${ }^{31}$ Deixei essa longa - mas necessária - nota para o final, com o objetivo de garantir fluidez ao texto. Citarei alguns trabalhos que de alguma forma versam sobre a utilização da mão de obra de retirantes em obras públicas em tempos de secas, situando as "obras contra as secas" entre as obras de socorros públicos. Primeiro, temos uma relevante dissertação desenvolvida entre os anos 2000 a 2003 que estuda o emprego de retirantes em construções organizadas localmente no estado do Ceará no século XIX, cujo objetivo de evitar a mendicância e também como forma de "educar para o trabalho" (SILVA, 2003). Posteriormente temos a pesquisa de Candido publicada em 2005. Um trabalho interessante centrado na construção da estrada de ferro de Baturité e no cenário de confrontos que lotou em seus serviços operários, retirantes e engenheiros (CANDIDO, 2005). Em seguida, temos outro grupo de trabalhos que se concentram nos estudos sobre a presença dos operários retirantes nas ditas "obras contra as secas", entre elas, obras permanentes e de emergência. O meu próprio trabalho desenvolvido no mestrado entre os anos 2007-2009 estuda a lida de retirantes-operários, engenheiros e sociedade local em frentes de emergências, centralizadas no governo federal, organizadas pela comissão de Obras Novas Contra as Secas (1915-1919) (FERREIRA, 2009), publicado pelo DNOCS/BNB em 2010. Temos ainda a dissertação que estuda a implantação do projeto de "combate as secas" da Inspetoria de Obras Contra as Secas (IOCS) através "das relações entre engenheiros civis e sociedade local nas obras de açudagem" (LIMA, 2010). Outro trabalho que trata dos embates e expectativas em torno da construção do açude Cedro, primeiro grande projeto de "combate às secas" no Brasil, discutindo também, entre outros, a irregularidade do trabalhador nas obras como entrave a sua conclusão (MONTEIRO, 2012). Recentemente defendida, a tese de Candido estuda os retirantes nas obras de estradas de ferro, mas também em "obras de combate às secas", entre elas a do açude Cedro (CANDIDO, 2014). Por fim, minha atual pesquisa de doutorado (em fase de conclusão) sobre a experiência de trabalhadores em obras permanentes e de emergência nas secas 1950.

${ }^{32}$ BIBLIOTECA PÚBLICA MENESES PIMENTEL. Setor de microfilmagem e Setor de Jornais. S/Título. Correio do Ceará, Fortaleza, 01 abr. 1951.
} 
então, recomeçavam as travessias em busca de novos serviços. Não obstante a falta da família, a convivência com o cenário das máquinas, a escassez de água, alojamentos precários, doenças e o serviço pesado e mal pago, o trabalho nas frentes representava a garantia do sustento, e isso era crucial. Para muitos, então, era necessário procurar as estradas e retomar o rastro das frentes de emergência, reconstruindo as formas alternativas de sobrevivência e possibilidades de algum ganho, garantindo, portanto, a vida.

Tudo leva a entender que o vai e vem das pessoas na rota das frentes de serviços já era consolidado como parte dos caminhos alternativos elaborados pelos pobres durante as estiagens da década de 1950. Certamente, esse é um dos importantes aspectos no entendimento da orquestração das obras como opção ao desemprego durante as estiagens. Paralelamente, outros vetores são os de condição política e econômica. Longe de menosprezar o papel do Estado e seus agentes, enquanto esfera de poder, gestor público e administrador, em cooperação com particulares, religiosos e políticos locais, deve-se lembrar de sua atuação incisiva rumo ao projeto de conter a migração para além das fronteiras do Nordeste, esforçando-se para exercer controle sobre a produção de riqueza, a mão de obra e os votos. Não é possível entender, portanto, o universo de trabalho construído nas obras durante as estiagens sem considerar a simultaneidade de fatores, as entranhadas relações desenhadas entre as ambições, projetos e atuações do Estado, com atenção também às escolhas, aos motivos e aos desejos das pessoas.

Sendo assim, as obras emergenciais foram o recurso principal da intensa política anti-migratória dos anos 1950. Instalando frentes de serviços em pontos considerados estratégicos, as autoridades desejavam conter os problemas que os retirantes poderiam causar com suas aglomerações, mas também desejavam tornar possível um manejo sobre os braços nordestinos. Dessa forma, com as obras de emergência, fazendeiros poderiam manter mão de obra disponível e se beneficiar com melhoramentos suas terras; e políticos assegurariam aos seus municípios recursos abonados, melhoramentos e votos.

Fora as construções estreadas para ocupar e fixar as pessoas em seus locais de origem, o Estado, por meio do MVOP, INIC, DNER e DNOCS, organizou-se para conter a saída de pessoas das fronteiras do Nordeste, acionando até a polícia para aparelhar as estradas e controlar o fluxo do êxodo. Assim, principalmente os que iam em direção ao Sudeste enfrentaram, além das dificuldades já conhecidas das longas 
travessias, um verdadeiro arsenal de estratégias para impedi-los de continuar seus trajetos, inclusive com o uso oficial da força. Mesmo assim, centenas de pessoas cruzaram os limites dos seus lugares de nascença, embora chegando aos seus destinos com bastante sofrimento.

Ademais, as vagas disponibilizadas nas frentes de emergência também podem ser consideradas entre as respostas às aglomerações de retirantes em busca por trabalho. Esses pobres, vivenciando uma seca - lida por intelectuais e políticos como fenômeno natural que descarrega suas mazelas sobre os indivíduos - e com fome, são refletidos, afinal, em muitos estudos, como indivíduos numa busca enlouquecida e desesperada para saciar suas necessidades vitais, tais quais os animais cassacos. Trocando em miúdos, é certo que as ações dos retirantes-operários são motivadas pela fome - o que para alguns parece atestar um patamar de irracionalidade. É certo também que não podem ser visualizadas como objetivando a ocupação de espaços institucionais, organizados metodicamente para a disputa e com discurso político articulado, o que faz com que se vista essas ações com o traje da espontaneidade. No entanto, muitas dessas pessoas conseguiram o que importava para elas naquele momento, e isso vale. E mesmo que suas lutas não provocassem respostas, esses sujeitos não poderiam ser relegados à margem da história.

Depois da busca por trabalho nas obras, aliás, outros detalhes do universo do trabalho dos retirantes nas frentes, em meio a fome, pesada lida, novos desafios e aprendizados também vão aparecer. 


\title{
Anti-migration policies and activism "migrant": tessitura between labor and migration in public works in dry times in Ceará (1950)
}

\begin{abstract}
About ten years after the "Batalha da Borracha" - when varguistas guidelines instituted a strong propaganda to boost the return of Northeastern workers towards rubber production in the Amazon - Ceará public and private authorities, strengthening the national government, have moved to stem the flow of large population of the state, through anti - immigration initiatives. During droughts in the 1950s, a large measure of attachment of workers was widespread installation of fronts emergency services. Indeed, as also matched the speech streamline aid to refugees without service and without food during droughts. Beside this, one might think that the migration route of public works has also become an alternative for the survival of workers who preferred to remain close to their places of origin to emigrate to other states.
\end{abstract}

Keywords: Labor; Migration; Policies.

\section{REFERÊNCIAS}

\section{Fontes primárias}

$1^{\circ}$ DR DNOCS. Açudes Públicos Ceará. Documentação do processo de construção das obras: relatórios de serviços, tabelas e gráficos, ofícios, telegramas, cartas e memórias justificavas (das obras). Açude Araras. Pastas 1; 3; 4.

$1^{\circ}$ DR DNOCS. Açudes Públicos Ceará. Documentação do processo de construção das obras: relatórios de serviços, tabelas e gráficos, ofícios, telegramas, cartas e memórias justificavas (das obras). Açude Pentecostes. Pastas 1; 2; 3.

$1^{\circ}$ DR DNOCS. Açudes Públicos Ceará. Documentação do processo de construção das obras: relatórios de serviços, tabelas e gráficos, ofícios, telegramas, cartas e memórias justificavas (das obras). Açude Orós, Pastas 6; 12.

$1^{a}$ DR DNOCS. Açudes Públicos Ceará. Açude Araras. Correspondência enviada pelo engenheiro Rômulo Campos ao Diretor Geral do DNOCS. 11 de agosto de 1951.

$1^{\text {a }}$ DR DNOCS. Açudes Públicos Ceará. Açude Araras. Telegrama enviado pelo prefeito de Cariré (CE), 6 de novembro de 1951.

BIBLIOTECA PÚBLICA MENESES PIMENTEL. Setor de microfilmagem e Setor de Jornais. Getúlio cada vez mais impressionado com a ameaça da seca no Ceará. Correio do Ceará, Fortaleza, 09 mar. 1951. 
BIBLIOTECA PÚBLICA MENESES PIMENTEL. Setor de microfilmagem e Setor de Jornais. Também de Nova Russas chegam as mais desoladoras notícias de fome. Correio do Ceará, Fortaleza, 16 mar. 1951.

BIBLIOTECA PÚBLICA MENESES PIMENTEL. Setor de microfilmagem e Setor de Jornais. Ataque a propriedade privada. Correio do Ceará, Fortaleza, 30 maio 1951.

BIBLIOTECA PÚBLICA MENESES PIMENTEL. Setor de microfilmagem e Setor de Jornais. S/Título. Correio do Ceará, Fortaleza, 01 abr. 1951.

BIBLIOTECA PÚBLICA MENESES PIMENTEL. Setor de microfilmagem e Setor de Jornais. Muito mais seca a Zona Norte. Correio do Ceará, Fortaleza, 26 maio 1951.

BIBLIOTECA PÚBLICA MENESES PIMENTEL. Setor de microfilmagem e Setor de Jornais. Flagelados famintos invadem cidades. Correio do Ceará, Fortaleza, 18 mar. 1958.

BIBLIOTECA PÚBLICA MENESES PIMENTEL. Setor de microfilmagem e Setor de Jornais. Mínimo trinta mil cearenses deixarão estado assolado pela seca. Gazeta de Notícias, Fortaleza, 01 abr. 1958.

BIBLIOTECA PÚBLICA MENESES PIMENTEL. Setor de microfilmagem e Setor de Jornais. S/Título. O Democrata, Fortaleza, 31 ago. 1951.

BIBLIOTECA PÚBLICA MENESES PIMENTEL. Setor de microfilmagem e Setor de Jornais. S/Título. O Democrata, Fortaleza, 16 out. 1951.

BIBLIOTECA PÚBLICA MENESES PIMENTEL. Setor de microfilmagem e Setor de Jornais. O Governo dará trabalho a todo flagelado. O Povo, Fortaleza, 23 mar. 1951.

BIBLIOTECA PÚBLICA MENESES PIMENTEL. Setor de microfilmagem e Setor de Jornais. Exploração de flagelados por motorista. Tribuna do Ceará, Fortaleza, 03 abr. 1951.

DEPARTAMENTO NACIONAL DE OBRAS CONTRA AS SECAS. Relatório de obras executadas em 1951. (apresentado pelo Diretor Berredo Vinícius). Rio de Janeiro: DNOCS/MVOP, 1951.

MINISTÉRIO DA VIAÇÃO E OBRAS PÚBLICAS. Relatório das atividades de 1952. (apresentado ao Presidente da República pelo Eng. Álvaro de Souza Lima ministro da Viação e Obras Públicas). Rio de Janeiro: MVOP/Serviço de Documentação, 1953.

PASSOS, José Candido Castro Parente Pereira. Departamento Nacional de Obras Contra as Secas. Boletim Institucional DNOCS, Rio de Janeiro, v. 19, n. 3, p. 32, fevereiro de 1959.

PASSOS, José Candido Castro Parente Pereira. Ministério da Viação e Obras Públicas. Departamento Nacional de Obras Contra as Secas. Boletim Institucional DNOCS, Rio de Janeiro, v. 18, n. 2, novembro de 1958. 
PASSOS, José Candido Castro Parente Pereira. Ministério da Viação e Obras Públicas. Departamento Nacional de Obras Contra as Secas. Boletim Institucional DNOCS, Rio de Janeiro, agosto de 1959.

PASSOS, José Candido Parente Pereira. Relatório de obras executadas em 1960. Rio de Janeiro: DNOCS, 1960.

PASSOS, José Candido Parente Pereira. Relatório de obras executadas em 1959. Rio de Janeiro: DNOCS, 1960.

PINHEIRO, Luiz Carlos Martins. Obras contra os efeitos das secas (seca de 1958). Boletim Institucional DNOCS [Separata], Rio de Janeiro, v. 19, n. 3, fevereiro de 1959.

PINHEIRO, Luiz Carlos Martins. Obras contra os efeitos das secas (seca de 1958). Boletim Institucional DNOCS [Separata], Rio de Janeiro, v. 19, n. 3, março de 1959.

SABOYA, Francisco. Relatório de serviços executados em 1950. Ministério da Viação e Obras públicas. Rio de Janeiro; Departamento Nacional de Obras Contra as Secas, 1951.

\section{Fontes secundárias}

ALBUQUERQUE JR, Durval. Nos destinos da fronteira: histórias espaços e identidade regional. Recife: Bagaço, 2008.

ALMEIDA, Beto. O século do DNOCS. Revista Conviver Nordeste Semiárido (DNOCS/BNB-ETENE), Fortaleza, v. 1, n. 6, 2009.

ALMEIDA, José Américo. Secas no Nordeste. Rio de Janeiro: Ministério da Viação e Obras Públicas. 1953.

ALVES, Joaquim. História das secas - séc. XVII a XIX. Edição fac-símile. Fortaleza: Fundação Waldemar Alcântara, 2003.

BARREIRA, Luciano. Os Cassacos. Rio de Janeiro: Nova Cultura, 1976.

BENCHIMOL, Samuel. Amazônia: um pouco - antes e além depois. Manaus: Ed. Umberto Calderaro, 1977.

BERREDO, Vinicius. Obras contra as secas. S/l: Departamento Nacional de Obras Contra as Secas. 1951.

BREFE, Ana Cláudia F. As cidades brasileiras no pós-guerra. São Paulo: Atual Editora, 1995.

CAMARGO, Aspácia. O Nordeste e a Política: diálogo com José Américo de Almeida. Rio de janeiro: Nova Fronteira, 1984. 
CÂNDIDO, Tyrone Apollo Pontes. Trem da Seca: Sertanejos, Retirantes e Operários (1877-1880). Fortaleza: Museu do Ceará. Secretaria da Cultura do Estado do Ceará, 2005.

CANDIDO, Tyrone. Proletários das secas: arranjos e desarranjos na fronteira do trabalho (1877-1919). 2014. Tese (Doutorado em História) - Universidade Federal do Ceará, Programa de Pós-Graduação em História, Fortaleza, 2014.

CARDOSO, Antonio Alexandre Isidio. Nem sina, nem acaso: a tessitura das migrações entre a Província do Ceará e o território amazônico. 2011. Dissertação (Mestrado em História Social) - Universidade Federal do Ceará, Programa de Pós-Graduação em História, Fortaleza, 2011.

CARVALHO, Rejane V. Aciole. O estado, a terra e o coronelismo. Rio de Janeiro: Coleção Mossoroense. Série C. Volume DCCI, 1991a.

CARVALHO, Rejane V. Aciole. A seca e os movimentos sociais. Coleção Mossoró: fundação Guimarães Duque, 1991b.

CASTRO, Lara de. "Avalanches de flagelados" no sertão cearense: retirantesoperários e engenheiros na lida das obras contra as secas. Série Conviver n. 12. Fortaleza: DNOCS/BNB-ETENE, 2010.

COSTA, Pedro Eymar Barbosa; GONÇALVES, Adelaide (Org.). Mais borracha para a vitória. Fortaleza; Brasília: MAUC/NUDOC/ Ideal Gráfica, 2008.

CUNHA, Euclides da. Os Sertões: campanha de Canudos. 20. Ed. Rio de Janeiro: Ediouro, 1998.

CUNHA, Euclides da. À margem da história: Euclides da Cunha. São Paulo: Martins Fontes, 1999.

DANTAS, Paulo. Viagem definitiva a Canudos. IN: DANTAS, Paulo. Capitão Jagunço. São Paulo. Ed. Global. 1982.

DUQUE, Guimarães. Solo e água no polígono das secas. 6 ed. Fortaleza: Banco do Nordeste do Brasil, 2004.

FERREIRA, Lara Vanessa de Castro. Enxadas e compassos: seca, ciência e trabalho no sertão cearense (1915-1919). 2009. Dissertação (Mestrado em História) Universidade Federal da Bahia, Programa de Pós-graduação em História, Salvador, 2009.

ESTEVAM NETTO, José. DNOCS ontem e hoje - sustentáculo da nascente civilização da seca. João Pessoa: DNOCS, 1987.

GEERTZ, Clifford. A Interpretação das Culturas. Rio de Janeiro: Guanabara, 1989.

GUERRA, Felipe. As Secas. Natal: Typ d’. “a Republica”, 1932. 
GUERRA, Felipe. Ainda o Nordeste. Natal: Typ d’. "a Republica”, 1927.

GUERRA, Felipe; GUERRA, Teófilo. Secas contra a seca. Rio de Janeiro: Tip. Cruz Coutinho, 1909.

GUERRA, Felipe; GUERRA, Teófilo. Secas do Nordeste. Natal: Centro de Imprensa, 1951.

GUERRA, Paulo de Brito. A Civilização da Seca: o Nordeste é uma história mal contada. Fortaleza: DNOCS, 1981.

GUERRA, Paulo de Brito. Açudes públicos do Nordeste, relação dos reservatórios construídos até 1981. Fortaleza: DNOCS,1982.

GUERRA, Paulo de Brito. Flashes da Seca. Fortaleza: DNOCS, 1983.

GIRÃO, Raimundo. Pequena História do Ceará. 4ed.Foratelza:Ed. UFC,1984.

HOBSBAWN, Eric. Os trabalhadores. Estudos sobre história do operariado. Rio de Janeiro: Paz e Terra, 1981.

HOBSBAWN, Eric. Bandidos. 2 ed. Rio de Janeiro: Forense Universitária,1976.

HOBSBAWN, Eric. Rebeldes Primitivos. Estudos de formas Arcaicas de Movimentos Sociais. 2 ed. Rio de Janeiro: Zahar, 1978.

HOBSBAWN, Eric. Mundos do trabalho. São Paulo: Paz e Terra. 2008.

LAMARTINE DE FARIA. Oswaldo. Cassacos. In: IBGE; CONSELHO NACIONAL DE GEOGRAFIA. Tipos e aspectos do Brasil: coletânea da Revista Brasileira de Geografia. 8 ed. Rio de Janeiro: IBGE, 1966.

LIMA, Aline Silva. Um projeto de combate as secas: os engenheiros civis, as obras públicas na Inspetoria de Obras Contra as Secas-IOCS e a construção do Açude Tucunduba (1909-1919). 2010. 124 f. Dissertação (Mestrado em História) Universidade Federal do Ceará, Programa de Pós-Graduação em História Social, Fortaleza, 2010.

MEDEIROS FILHO, João; SOUZA, Itamar de. A seca do Nordeste: um falso problema. A política de combate às secas antes e depois da SUDENE. Petrópolis: Vozes, 1988.

MONTEIRO, Renata Felipe. Um monumento ao Sertão: ciência, política e trabalho na construção do açude Cedro (1884-1906). 2012. Dissertação (Mestrado em História) Universidade Federal do Ceará, Programa de Pós-Graduação em História, Fortaleza, 2012. 
MONTENEGRO, João Alfredo de Sousa. O DNOCS em ação (irrigação e emergência). In: NÚCLEO INDEPENDENTE DE ESTUDOS E PESQUISAS DO CEARÁNIEPCE. O DNOCS e o novo Nordeste: uma perspectiva histórica, 1909-1984. Fortaleza: DNOCS, 1985.

NEVES, Frederico de Castro. Curral de bárbaros: os campos de concentração no Ceara (1915 e 1932). Revista Brasileira de História, São Paulo, v. 15, n. 29, p. 93-122, 1995.

NEVES, Frederico de Castro. Economia moral versus moral econômica: o que é economicamente moral para os pobres? Projeto História, São Paulo, n. 16, p. 39-57, 1998.

NEVES, Frederico de Castro. A multidão e a história: saques e outras ações de massas no Ceará. Rio de Janeiro: Relume Dumará, 2002.

NEVES, Frederico de Castro. Seca, Pobreza e Política: o que é politicamente correto para os pobres? Trajetos (UFC), Fortaleza, v. 7, n. 13, p. 186-201, 2009.

PERROT, Michelle. Os excluídos da História. Operários, mulheres, prisioneiros. Rio de Janeiro: Paz e Terra, 1988.

RAMOS, Graciliano. Vidas Secas. 51 ed. São Paulo: Record, 1983.

RIBEIRO, Gustavo Lins. O Capital da Esperança: experiências de trabalhadores na construção de Brasília. Brasília: UNB.

RIOS, Kênia Souza. Campos de concentração no Ceará: Isolamento e poder. Fortaleza: Museu do Ceará/SECULT, 2002.

ROSADO, Vingt-um (Org.). Memorial da Seca. Vol. CLXIII. Mossoró: Coleção Mossoroense, 1981.

ROSADO, Vingt-um (Org.). 12 livro das secas. Vol. CCCVI. Mossoró: Editora Universitária. Coleção Mossoroense, 1985.

ROSADO, Vingt-un; ROSADO, América. Décimo primeiro livro das secas. Natal: ESAM, 1985. (Coleção Mossoroense, 305). 271p.

ROSADO, Vingt-um; ROSADO, Américo. Vol. CDII. $\mathbf{1 7}^{\mathbf{0}}$ livro das secas. Mossoró: Editora Universitária, 1988. (Coleção Mossoroense).

RUDÉ, George. A Multidão na História: estudo dos movimentos populares na França e na Inglaterra, 1730-1848. Rio de Janeiro: Campus, 1991.

SECRETO, Maria Verónica. Ceará, a fábrica de trabalhadores: Emigração subsidiada no final do Século XIX. Trajetos (UFC), Dossiê: trabalho, trabalhadores, Fortaleza, v. 2, n. 4, p. 47-65, 2003.

SECRETO, María Verónica. Soldados da Borracha. Trabalhadores entre o sertão e a Amazônia no governo Vargas. São Paulo: Editora Fundação Perseu Abramo, 2007. 
SILVA, Jeovah Lucas da. As Bênçãos de Deus: a seca como elemento educador para o trabalho (1877-1880). 2003. Dissertação (Mestrado em História Social) - Universidade Federal do Ceará, Programa de Pós-graduação em História, Fortaleza, 2003.

SOBRINHO, Thomaz Pompeu. A Fome: Cenas da seca no Ceará. Rio de Janeiro: Imprensa Inglesa, 1922.

SOBRINHO, Thomaz Pompeu. História das Secas (século XX). Vol. CCXXV. Mossoró: Editora Universitária, 1982. (Coleção Mossoroense).

THOMPSON, Edward Palmer. Costumes em Comum. São Paulo: companhia das letras, 1998.

Recebido em novembro de 2014.

Aprovado em maio de 2015. 